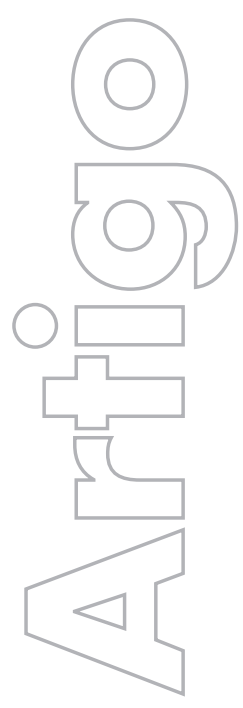

Usos do território e o papel do Estado no Brasil: notas sobre a atuação da Agência Desenvolve SP

\author{
Fabrício Gallo \\ Deplan/IGCE/Unesp
}

revista

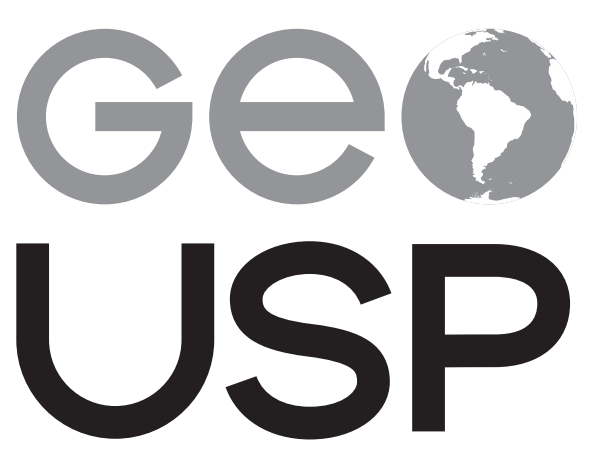

espaço e tempo

Volume $21 \cdot n^{\circ} 2$ (2017)
Como citar este artigo:

GALLO, F. Usos do território e o papel do Estado no Brasil: notas sobre a atuação da Agência Desenvolve SP. Geousp Espaço e Tempo (Online), v. 21, n. 2, p. 480-496, agosto. 2017. ISSN 2179-0892.

p. $480-496$

Disponível em: < http://www.revistas.usp.br/geousp/ article/view/119737>. doi: 10.11606/issn.2179-0892. geousp.2017.119737.

\section{(c) $(1) \Theta$}

Este artigo está licenciado sob a Creative Commons Attribution 4.0 License. 


\title{
Usos do território e o papel do Estado no Brasil: notas sobre a atuação da Agência Desenvolve SP1
}

\section{Resumo}

Neste artigo, inicia-se uma reflexão sobre a composição e o papel do Estado como agente significativo no processo de uso do território no período atual. Como compromisso analítico, sugere-se um estudo da reorganização das solidariedades federativas no território brasileiro a partir da forte presença econômica do ente federativo estado de São Paulo (Brasil). Entender o uso do território e o papel do Estado paulista como esfera normativa, reguladora e provedora de recursos aos municípios e às empresas localizadas em seus limites é um dos propósitos deste texto. Esse processo se verificará a partir de financiamentos liberados pela Agência de Desenvolvimento Paulista, a Desenvolve SP, para a renovação seletiva das materialidades e a ampliação dos investimentos das empresas localizadas em municípios paulistas.

Palavras-chave: Usos do território. Federalismo brasileiro. Geografia política. Estado brasileiro.

\section{Uses of territory and role of State in Brazil. Notes about the operations of the Agência Desenvolve SP}

\begin{abstract}
The text aims to initiate a reflection about the composition and role of the State as a significant agent in the process of use of territory. As analytical compromise is suggested a study of the reorganization of federal solidarities in Brazil, from the strong economic presence of the federative entity "state of São Paulo". One of the challenges of this text is to understand the use of territory and the role of the São Paulo as normative sphere, regulatory and provider of resources to municipalities and companies located in this state. This process will be verified from the resources and financing released by the Agência de Desenvolvimento Paulista (Desenvolve SP), for selective renovation of materialities and the expansion of investments in companies located in the counties.
\end{abstract}

Keywords: Uses of territory. Brazilian federalism. Political Geography. Brazilian State.

1 Este artigo apresenta parte dos resultados da pesquisa científica financiada pela Fapesp (Fundação de Amparo à Pesquisa do Estado de São Paulo) na modalidade "Auxilio Regular à Pesquisa". 


\section{Introdução}

Neste texto buscamos discutir alguns aspectos do processo de (i) financiamento da renovação das materialidades no território brasileiro (Santos; Silveira, 2001) e (ii) financiamento da ampliação produtiva - com especial enfoque no estado de São Paulo - a partir dos recursos repassados pela Agência de Desenvolvimento Paulista, a Desenvolve SP. Dessa temática se desdobra o compromisso analítico de buscar compreender o papel ativo do território na reorganização das solidariedades federativas.

Para tal análise este processo será verificado a partir dos financiamentos liberados oriundos de agências de desenvolvimento estatais. Tais fatos ampliam a densidade técnica do território (Santos, 2002) sendo que, segundo Santos e Silveira (2001, p. 294-295):

[...] esse processo de construção-destruição-reconstrução de diferenciações e hierarquias conduz a frequentes desvalorizações e revalorizações de partes do território, quando o encaramos do ponto de vista da sua participação na prática de uma competitividade global.

Para tanto, apontamos a necessidade de trabalharmos com alguns referenciais teóricos, a partir dos quais se procurará desenvolver a estrutura do debate que se propõe. Assim, compartilhamos a visão de Santos (1994) de que o território não é uma entidade pura, não é apenas natureza, não apenas político, não é apenas econômico ou cultural, tão pouco é homogêneo. Por isso, considera-se no presente projeto que o conceito território usado (Santos, 1999a, 2002; Santos et al., 2000; Silveira, 2009, 2011; Ribeiro, 2003; Cataia, 2011, 2013) se apresenta como instrumento analítico relevante, pois "o território usado, visto como uma totalidade, é um campo privilegiado para a análise na medida em que, de um lado, nos revela a estrutura global da sociedade e, de outro lado, a própria complexidade do seu uso" (Santos et al., 2000, p. 12). Tal noção é uma ferramenta significativa na tarefa de se analisar sistematicamente a constituição do território na medida em que incorpora todos os atores, constituindo-se, portanto, numa totalidade cindida em duas matrizes: de um lado as materialidades (ou configuração territorial) e, por outro lado, as imaterialidades, constituídas pelas ações políticas, tanto as pretéritas quanto as contemporâneas.

De acordo com María Laura Silveira (2011) este se trata de um processo solidário e contraditório entre existências técnicas e normativas, advindas do passado remoto ou recente, e possibilidades do nosso período. Ainda segundo a autora (Silveira, 2009), os objetos e normas nos chegam do passado, mas as ações "presentificam" esses mesmos objetos dotando-os de novos conteúdos e intencionalidades ou mesmo criando novas existências. Por isso, Silveira aponta que um gerúndio se faz necessário, ou seja, que interpretemos o território sendo usado já que, "nesse sistema de ações, o futuro se instala e o território torna-se, ainda mais, um híbrido" (Silveira, 2009, p. 131).

\section{Proposta de entendimento do Estado como agente significativo na viabi- lidade dos usos do território}

Partindo da concepção de que o território brasileiro é o produto e a condição de uma difusão seletiva do meio técnico-científico-informacional (Santos, 2002), para buscarmos o entendimento de como o território vem sendo usado no período contemporâneo, verifica-se a 
necessidade de identificar os distintos poderes que têm os agentes neste processo. No que tange ao uso do território, Santos (2002) identifica agentes que têm poder de ação sobre o território como um todo (os agentes hegemônicos) e aqueles cujo poder é mais limitado espacial e temporalmente, estes são os agentes não hegemônicos. Para estes últimos o território seria seu abrigo, já para os primeiros o território seria um recurso (Gottmann, 2012).

Em nossa visão, um dos agentes mais significativo no exercício do poder de uso do território é o Estado, pois para o exercício do poder são necessários meios para fazê-lo e este é o agente que organiza o território por meio de seu poder de regulação do dinheiro, dos financiamentos, da lei e da política. ${ }^{2}$ No entanto, faz-se conveniente salientar o alerta de Cataia (2013, p. 1146) de que muitas fontes do poder que não se localizam no interior das instituições do Estado. Este autor ressalva para não se cometer o erro já apontado por Raffestin (1993) de interpretar o Estado como a única fonte do poder.

Essas outras fontes do poder - ou, seria melhor dizer, que disputam o poder incluem os agentes hegemônicos - como as grandes empresas - e os agentes não hegemônicos, que incluem a grande maioria dos movimentos sociais e todos aqueles que, não organizados na forma de "movimentos sociais", são invisibilizados pelos agentes hegemônicos (Cataia, 2013, p. 1146).

Antas Jr. (2005) nos lembra que no período atual, caracterizado pelo processo de saída do Estado de alguns setores por meio de privatizações e concessões de serviços públicos ao capital privado, encontramos elementos de uma regulação hibrida do território, já que, mesmo depois das privatizações e concessões, o Estado permanece em seu papel regulador, conforme aos mecanismos tradicionais, mas a partir da criação de novos mecanismos de regulação para estes setores e que pode determinar uma regulação do território com forte direcionamento para a lógica de mercado (o autor cita, como exemplo, a criação das Agências Nacionais de Regulação: Anatel, Aneel, ANP, ANS, Anvisa etc.).

A partir das considerações anteriormente mencionadas e da necessidade de se entender o Estado frente ao poder do capital privado, acreditamos que para nosso propósito faz-se necessário iniciar uma reflexão - que não pretende esgotar o tema - acerca da composição e do papel do Estado como agente significativo no processo de uso do território no período contemporâneo.

Em estudo clássico, Engels (1977, p. 191) já indicava que "o Estado não é pois, de modo algum, um poder que se impôs à sociedade de fora para dentro [...]. É antes um produto da sociedade quando esta chega a um determinado grau de desenvolvimento". Weber (1991) nos explicou que o Estado reclama para si o monopólio legítimo da violência para impor seus projetos, mas Poulantzas (1977), desenvolvendo a concepção de Estado trazida por Marx e Engels, adverte que o Estado é possuidor de certa autonomia relativa, no entanto assevera que este não pode dominar as classes exploradas pelo simples emprego da violência por meio da força física. Segundo ele, "esta violência deve

2 É conveniente mencionar que outros relevantes pesquisadores também se propuseram a desvendar a natureza do Estado moderno. Nossa intenção não é esgotar as diferentes interpretações sobre o Estado, afinal, muitas teses poderiam se originar nessa tentativa, buscamos apenas apontar que a interpretação do Estado como agente importante - mas não único - de uso do território é um caminho para ampliar o entendimento das transformações territoriais no período contemporâneo. 
sempre se apresentar como legítima, por uma atuação, por meio do Estado, da ideologia dominante capaz de provocar um certo consenso da parte de algumas classes e frações dominadas" (Poulantzas, 1977, p. 13-14).

Na leitura de Poulantzas (2000), o Estado teria, em relação às classes dominantes, um papel principal de organizador.

Organização, na perspectiva do Estado, da unidade conflitual da aliança de poder e do equilibrio instável dos compromissos entre seus componentes, o que se faz sob a hegemonia e direção, nesse bloco, de uma de suas classes ou frações, a classe ou fração hegemônica. $\bigcirc$ Estado constitui, portanto, a unidade política das classes dominantes: ele instaura essas classes como classes dominantes (Poulantzas, 2000, p. 129).

Por isso que, para esse autor, o Estado pode ser decifrado a partir de duas visões clássicas: uma primeira sendo considerado o instrumento da classe dominante que manipula o aparelho estatal para garantir o desenvolvimento da economia com os privilégios de classe; já a outra visão diz respeito ao Estado institucionalista, aquele que funciona com poder próprio, autônomo e com racionalidade própria.

Essas duas dimensões de interpretar o Estado carregam a noção de que este nasce como instrumento de classes, todavia, o bloco no poder ${ }^{3}$ utiliza-se da ideologia como forma de manutenção do poder e de garantia do próprio Estado:

[...] nas práticas materiais, nos hábitos, nos costumes, nos modos de vida de uma formação social. Enquanto tal, e na medida em que as relações ideológicas constituem, elas também, as relações de poder absolutamente essenciais à dominação de classe, a ideologia dominante se materializa e se encarna nos aparelhos de Estado (Poulantzas, 1977, p. 13).

Sobre essa atuação hegemônica da classe dominante 4 (ou de uma fração dela), Décio Saes (1998) nos ensina que a hegemonia de uma fração da classe dominante só pode ser detectada no nível estatal.

3 Segundo Poulantzas (2000, p. 129), o bloco no poder é aquele composto de várias frações de classe burguesas (pois a burguesia é dividida em frações de classe), do qual participam, em certas circunstâncias, as classes dominantes provenientes de outros modos de produção, presentes na formação capitalista". Saes (1998, p. 47) nos afirma que esse conceito indica "que a unificação política das classes proprietárias contra as classes trabalhadoras não exclui a submissão política (ou 'hegemonia' no sentido estrito) de certas frações de classe dominante à fração de classe dominante mais poderosa".

4 A noção de hegemonia foi debatida por um conjunto significativo de autores. No entanto, foi Gramsci (2002a, 2002b) quem melhor desenvolveu a temática defendendo a ideia de uma construção progressiva da hegemonia. $\bigcirc$ autor aponta que um grupo social pode e deve se tornar dirigente antes mesmo da conquista do poder estatal sendo que, na sequência, "quando exerce o poder e mesmo se o mantém fortemente nas mãos, torna-se dominante, mas deve continuar a ser também dirigente" (Gramsci, 2002a, p. 62-63). Ainda segundo Gramsci (2002a, p. 62, grifos do autor), "a supremacia de um grupo social se manifesta de dois modos, como domínio e como direção intelectual e moral. Um grupo social é dominante dos grupos adversários que tende a liquidar ou a submeter também mediante a força armada; e é dirigente dos grupos afins ou aliados". Ramos (2005, p. 26), fazendo referência a Gruppi (1978), aponta que "a originalidade de Gramsci repousa, entre outros aspectos, no fato de que Gramsci foi o primeiro a aplicar o conceito de hegemonia também à burguesia, ou seja, aos mecanismos de exercício da hegemonia das classes dominantes. Segundo Gramsci, as relações capitalistas de produção podem ser mantidas sob condições democráticas e, consequentemente, a exploração pode ser mantida com o consentimento dos explorados. É partindo dessas afirmações que Gramsci desenvolve o conceito de hegemonia, que emerge basicamente como capacidade de entender os problemas reais do homem e de não limitar-se a uma expectativa passiva das consequências decorrentes das leis gerais que governam o capitalismo, sendo assim uma chave na leitura e na análise de processos históricos" (Gruppi, 1978). 
Mais precisamente: só a análise da política de Estado nos permite definir quem (isto é, que fração da classe dominante) é hegemônico no seio da classe dominante. Todavia, como já afirmamos anteriormente, existe um aspecto determinado da política de Estado que não permite essa definição, na medida em que ele corresponde ao interesse geral comum a todas as frações da classe dominante: trata-se da política da ordem, isto é, da defesa da Ordem Social fundada na propriedade privada. Assim, é sobretudo ao nível da política do desenvolvimento que se pode encontrar os indícios de uma situação hegemônica; ou seja, ao nível daquilo que se convencionou chamar de política econômica (decisões do Estado concernentes às frações do capital e à terra) e de política social (decisões do Estado concernentes às classes trabalhadoras e, evidentemente, contidas dentro dos limites postos pelo exercício da função política mais geral de instauração/conservação da Ordem Social) (Saes, 1998, p. 81-82).

Para esse mesmo autor, seria hegemônica a fração detentora do controle da política de Estado, aquela que define uma política de desenvolvimento prioritariamente favorável aos seus interesses como fração.

Na visão de Liguori5 (2003, p. 181 apud Moraes, 2010) "a plena explicitação da função hegemônica só ocorre quando a classe que chegar ao poder se torna Estado: o Estado serve-lhe tanto para ser dirigente quanto para ser dominante".

É Kostas Vergopoulos (1982, p. 63), partindo da concepção marxista, quem alerta que a sociedade ocidental não se unifica somente pelo Estado, mas por vínculos reais oriundos do interesse individual. Assim, aponta que o "conjunto social subdesenvolvido se unifica pela materialidade das articulações, que permanecem, no entanto, exteriores a cada uma das formas. Aqui, o Estado resulta não do conjunto de formas e estruturas, mas do conjunto de articulações". Na mesma linha de raciocínio Bob Jessop (2002, p. 40) define o Estado como "um conjunto relativamente unificado de instituições, organizações, forças sociais e atividades socialmente enraizadas".

Para Limonad (2014) o Estado pode ser entendido, simultaneamente, como o resultado e arena de interação de forças e de interesses sociais que podem ser diversos e contraditórios, por isso: [...] sua forma institucional é uma resultante e um condicionante, da correlação de forças e das estratégias dos diferentes atores sociais e políticos, onde as forças hegemônicas fazem valer suas estratégias inscritas territorialmente e articuladas em diferentes escalas, estratégias estas selecionadas de forma seletiva em conformidade com as alianças prevalecentes no bloco do poder (Limonad, 2014, p. 8).

Tal visão se completa com a afirmação de Pinto e Balanco (2014) de que o Estado representa a combinação, em diferentes graus, e determinada por uma conjuntura espacial e temporal, de dois grandes eixos: autonomia da administração central X subordinação do Estado a determinados interesses.

5 LIGUORI, G. Estado e sociedade civil: entender Gramsci para entender a realidade. In: COUTINHO, C. N.; TEIXEIRA, A. P. (Org.). Ler Gramsci, entender a realidade. Rio de Janeiro: Civilização Brasileira, 2003. p. 173-188. 
Por isto, uma reflexão de María Laura Silveira (2011, p. 83) se faz relevante: a autora adverte que o uso do território no período contemporâneo nunca foi tão seletivo pois pune as camadas mais pobres já que, ao mesmo tempo, faz a transferência de dinheiro público e social para sistemas de engenharia necessários à produção moderna e à organização do comércio exterior. Essa ponderação se coaduna com a proposição de Castells (1977) de que a intervenção do Estado no consumo coletivo o transforma naquele que ordena os equipamentos e infraestruturas do cotidiano urbano, assim, o Estado passaria a atuar, de maneira ampliada, intervindo direta ou indiretamente no processo produtivo. Ainda segundo este autor, "a intervenção do Estado no urbano, que se queira um elemento regulador, torna-se uma nova fonte de contradições e de conflitos a nível do conjunto das camadas populares. Assim, exprime e ao mesmo tempo acelera a crise do Estado capitalista" (Castells, 1977, p. 167).

Não nos propomos aqui a formular uma teoria do Estado, tampouco reformular os debates existentes na ciência política, nossa sugestão é a de que podemos pensar, a partir dos autores acima mencionados, que uma relação sistêmica se instala para a viabilidade dos diversos projetos de uso do território pelos distintos agentes - sobretudo por aqueles com maior poder de ação. De um lado as empresas, corporações e agentes privados buscam no Estado o recurso, o dinheiro público, o instrumental normativo e legislativo favorável para o desenvolvimento e viabilidade de seus projetos, afinal é o Estado aquele que fornece infraestruturas produtivas e de escoamento de produção; capital de giro, financiamentos e empréstimos em programas de desenvolvimento econômico (por muitas vezes subsidiados); flexibilização normativa (produtiva, trabalhista, ambiental etc.) para estimular a competitividade em escalas local, nacional e global. De outro lado, uma elite se instala, se apodera do aparelho estatal e, a partir deste instrumento, se mantém como classe dominante.

Acreditamos ser possível dizer que um sistema de usos do território se instala já que uma relação de mutualidade se realiza, isto é, o processo de uso do território não se realiza isoladamente por um ou outro agente, já que uma complexa rede de articulações (lícitas ou não, visíveis ou não) acaba por se estabelecer e, em muitas, o Estado está presente - direta ou indiretamente. As corporações, instituições e agentes privados hegemônicos, para usar o território dependem da base do Estado para viabilizar e concretizar seus projetos; ao mesmo tempo, para se manter como elite dominante (que se efetiva pelo constante apoio do capital privado), a fração de classe que está no comando do Estado, atende aos interesses desses agentes corporativos por meio do aparato estatal. No âmbito desse complexo jogo de alianças e articulações entre esses agentes, aqueles que não são hegemônicos (ou que não conseguem se manter como hegemônicos) acabam excluídos dos processos decisórios.

\section{As solidariedades federativas, as articulações com agentes econômicos e o estado de São Paulo}

Voltando nosso debate para a compreensão das articulações entre o Estado brasileiro e os agentes econômicos no período atual, propomos refletir como que a arquitetura de nosso sistema federativo permite a instalação de complexas articulações que viabilizam um sistema de usos do território onde os projetos privados e estatal se desenvolvem mutuamente. A evolução do federa- 
lismo brasileiro (fruto, inicialmente, da influência e do poder das elites oligárquicas, dos diferentes textos constitucionais elaborados e das distintas competências atribuídas aos entes) aponta uma das formas de como o Estado brasileiro usa o território para efetivar o exercício do poder.

Para essa tarefa, propõe-se compreender o território usado pela ótica do Estado, sobretudo destacando o entendimento de que na República Federativa do Brasil os três níveis da Federação (União, estados-membros e os municípios) são "Estado".

A esses três níveis de governo são assegurados autonomia e competências legiferantes e administrativas, já que o princípio federativo parte da premissa de que todos são iguais entre si sem que haja qualquer hierarquia. Além da isonomia entre os entes, a Constituição Federal de 1988 thes garantiu autonomia e competências exclusivas (inclusive tributária) para tratar de determinados assuntos, estabelecidos constitucionalmente como próprios a cada ente.

Cataia (2013) nos alerta que, de certa maneira, temos que reconhecer que a Federação (sinônimo de poder público) deve ser entendida como:

[...] um sistema de ação e cada um de seus membros (União, estados e municípios) como subsistemas do sistema de ação federativo, cada um tendo sua esfera própria de ação. Assim, cada ente da Federação é um subsistema do sistema de ação federativo (Cataia 2013, p. 1145-1146).

Este autor ainda nos indica que:

[...] cada ente da Federação é um subsistema do sistema de ação federativo e em cada um deles orbitam "poderes periféricos" ou "poderes laterais" (Grémion, ${ }^{6}$ 1976; Sassen, ${ }^{7}$ 2010) e "elites do poder" (Mills, ${ }^{8} 1962$; Burztyn, ${ }^{9}$ 1987; Castro, ${ }^{10}$ 1992; Faoro," 2000), que, apesar de não serem membros da estrutura hierárquica interna de cada ente da Federação, fazem parte do sistema, porque têm poder para interferir na regulação e execução da renovação das materialidades, redesenhando assim a divisão do trabalho local (Cataia, 2013, p. 1146).

A manutenção do equilibrio de poder entre as esferas federativas - necessária devido a existência de dissimetrias econômicas -, impõe constantemente negociações políticas e pactos entre os entes. Sugere-se que do ponto de vista federativo não se pode compreender as dinâmicas locais sem uma mais justa compreensão das articulações entre as escalas de poder. Como aponta Vainer (2006, p. 28) "o poder, mais do que nunca [...] está na capacidade de articular escalas, de analisar e intervir de modo transescalar". Isso corrobora a assertiva de Harvey (2005) para quem a atenção não deve ser dirigida apenas ao governo local, pois o poder de organização da vida de uma cidade muitas vezes está em outra parte, em coalizões de forças mais amplas, em que o governo e administração locais desempenham apenas papel facilitador e coordenador.

6 GRÉMION, P. Le pouvoir périphérique: bureaucrates et notables dans le système politique français. Paris: Seuil, 1976.

7 SASSEN, S. Sociologia da globalização. Porto Alegre: Artmed, 2010.

8 MILLS, C. W. A elite do poder. Rio de Janeiro: Zahar, 1962.

9 BURZTYN, M. O poder dos donos. Vozes: Petrópolis, 1987.

10 CASTRO, I. E. O mito da necessidade: discurso e prática do regionalismo nordestino. Rio de Janeiro: Bertrand Brasil, 1992.

11 FAORO, R. Os donos do poder: formação do patronato político brasileiro. São Paulo: Globo/Publifolha, 2000. 
Como compromisso analítico para este texto é sugerida a análise da reorganização das solidariedades federativas no território brasileiro no período atual, a partir da forte presença econômica do estado de São Paulo. ${ }^{12}$ A interpretação dos recursos financeiros que promovem uma difusão seletiva das materialidades no estado de São Paulo ocorrerá por meio da análise daqueles recursos que, efetivamente, se transformaram em materialidades, se "geografizaram", se "espacializaram", ou seja, que se tornam "território". Nossa intenção é a de analisar as recentes ações das Agências Estaduais de Fomento (que no estado de São Paulo se chama Agência de Desenvolvimento Paulista, a Desenvolve SP). No caso brasileiro, com a descentralização tributária realizada a partir da Constituição de 1988, aqueles entes federados que já eram mais pujantes do ponto de vista orçamentário passam a ter aumentado seu poder de arrecadação e de influência sobre os outros. Isso fez aumentar o poder do estado de São Paulo, isto é, o poder econômico do governo paulista faz com que a arrecadação própria de tributos estaduais seja elevada.

Neste caso, faz-se necessária uma leitura do processo jurídico-institucional de formação das Agências Estaduais de Fomento. Segundo Galvão (2012), as agências de fomento têm origem na Resolução do Conselho Monetário Nacional de n. 2.574 (BCB, 1998), e, em seguida, na Resolução n. 2828 (BCB, 2001). Nesse contexto, essas agências surgem do programa de redução da presença do setor público na atividade bancária, instituído pelo Governo Federal Brasileiro por meio da Medida Provisória n. 1514 (Brasil, 1996), medida que sofreu inúmeras reedições e tem sua versão mais recente na Medida Provisória n. 2192-70 (Brasil, 2001), mas que mantém em seu contexto o foco central de redução da presença estatal na atuação bancária.

As agências de fomento têm suporte na Resolução do Conselho Monetário Nacional n. 2828 (BCB, 2001), tendo como objeto social, o financiamento de capital fixo e de giro, associado a projetos na Unidade da Federação onde tenham sede, e mais as características a seguir: (a) devem ser sociedades por ações de capital fechado; (b) subordinadas à supervisão e à fiscalização do Banco Central do Brasil, inclusive, somente podendo funcionar segundo autorização deste; (c) somente podem praticar operações com recursos próprios e de repasses originários de: fundos constitucionais, recursos orçamentários, organismos nacionais e internacionais de desenvolvimento; (d) permitida a prestação de garantias, a utilização da alienação fiduciária em garantia e de cédulas de crédito industrial e comercial, e a cobrança de encargos nos moldes praticados pelas instituições financeiras; (e) facultada a atuação como prestador de serviços de consultoria, agente financeiro e administrador de fundos de desenvolvimento, desde que sem a assunção de riscos.

O mesmo instrumento normativo trouxe ainda (à época de sua instituição) vedações importantes como: acesso às linhas de assistência financeira do Banco Central; acesso à conta Reservas Bancárias no Banco Central; captação de recursos junto ao público; contratação de depósitos interfinanceiros, tanto como depositante como depositário.

Convém ressaltar que a Resolução do Conselho Monetário Nacional n. 2828 (BCB, 2001) indica que a cada Unidade da Federação só cabe uma única agência de fomento sendo que o controlador deve manter fundo de liquidez equivalente, no mínimo,

12 Em debate recente, sob a ótica da geografia, Gallo (2014) mostra como a federação brasileira se estruturou e, de certa maneira, como o poder se concentrou no ente federado estado de São Paulo. A partir disso, propõe que a federação pode ser interpretada como um evento geográfico. 
a 10\% de suas obrigações e estes recursos deverão estar aplicados em Títulos Públicos Federais. Segundo Neto Ribeiro (2004), embora em termos legais estas agências não constituam instituições financeiras, elas estão subordinadas a legislação que regulamenta estas instituições, em especial destaque ao artigo 192 da Constituição Federal de 1988 (Brasil, 1988).

Conforme o Banco Central do Brasil (Bacen, [s.d.]), a definição oficial de agência de fomento é:

Tais entidades têm status de instituição financeira, mas não podem captar recursos junto ao público, recorrer ao redesconto, ter conta de reserva no Banco Central, contratar depósitos interfinanceiros na qualidade de depositante ou de depositária e nem ter participação societária em outras instituições financeiras. De sua denominação social deve constar a expressão "agência de fomento" acrescida da indicação da Unidade da Federação Controladora. É vedada a sua transformação em qualquer outro tipo de instituição integrante do Sistema Financeiro Nacional.

\section{A relevância e atuação da Agência Desenvolve SP}

No intuito de se buscar demonstrar e entender o poder econômico do ente federado estado de São Paulo (para com isso entendermos todo o processo de negociações na repartição e transferências desses recursos entre os municípios paulistas), faz-se importante entender o papel da Desenvolve SP. Um elemento que indica seu poder econômico dentro da federação brasileira é o apontamento de que por ser o estado que mais arrecada impostos na federação, além da possibilidade de formulação individual de um convênio entre o estado e qualquer um dos seus 645 municípios, observa-se em São Paulo a existência da Desenvolve SP, uma grande agência de fomento vinculada à Secretaria da Fazenda que foi instituída pela Lei Estadual n. 10.853 (São Paulo, 2001), regulamentada pelo Decreto n. 52.142 (São Paulo, 2007), criada em março de 2009 (depois da venda do Banco estadual Nossa Caixa) e que entrou em operação em julho de 2009 , quando realizou seu primeiro financiamento. ${ }^{13}$

Para entender o processo de criação desta agência, faz-se relevante apontar alguns fatos que marcaram a política econômica do Brasil nas décadas finais do século XX. Entre a promulgação da Constituição de 1988 e a implantação do Plano Real (em 1994), observou-se no país um equilibrio fictício nas finanças públicas (estaduais e municipais) devido ao descontrole causado pela alta inflação na economia brasileira. Isso ocorria porque, no caso das despesas públicas, a inflação corroía seu valor real em razão da defasagem de tempo entre o período da contratação dos serviços e de seu efetivo pagamento (Gallo, 2013). A alta inflação do período supracitado não teve início em 1988, na verdade ela antecede esse momento e tem origens na década de 1970 e se associa ao endividamento dos bancos estaduais que tem início em 1975 (e que se aprofunda no início da década de 1990).

13 Segundo o Banco Central do Brasil, em junho de 2014, estavam em operação 16 Agências Estaduais de Fomento (nos estados de Alagoas, Amazonas, Amapá, Bahia, Goiás, Mato Grosso, Pernambuco, Paraná, Piauí, Rio de Janeiro, Rio Grande do Norte, Rio Grande do Sul, Roraima, Santa Catarina, São Paulo e Tocantins) e três Bancos de Desenvolvimento (de Minas Gerais, do Espírito Santo e do Extremo Sul) (BCB, [s.d.]). 
Na tentativa da reversão desse quadro, em agosto de 1996 o governo federal brasileiro editou a Medida Provisória n. 1514 (Brasil, 1996) que criava o Proes (Programa de Incentivo à Redução do Estado na Atividade Bancária). A intenção desta medida era, conforme Salviano Jr. (2004, p. 81), "reduzir ao mínimo a presença de instituições financeiras controladas pelos governos estaduais no sistema financeiro", tendo em vista o enorme endividamento dos estados da federação à época. Ainda segundo Salviano Jr. (2004, p. 84), ao aderirem ao Proes os governadores dos estados poderiam dar os seguintes destinos aos seus bancos estaduais: (i) extinção da instituição financeira; (ii) privatização; (iii) transformação em instituição não financeira (agência de fomento); (iv) federalização da instituição financeira (isto é, a aquisição do controle pela União, que posteriormente poderia privatizar ou extinguir a instituição); e (v) saneamento da instituição.

Na visão de Contel (2011, p. 183) chama atenção para a transformação das instituições financeiras estaduais em "agências de fomento".

A partir do momento em que se constituem em Agências de Fomento, os antigos bancos estaduais passam a ser considerados ainda - do ponto de vista jurídico como "instituições não financeiras". A grande novidade, no que diz respeito à ação das "Instituições não financeiras", é que estas não podem se endividar, como era o caso dos bancos estaduais. Seu controle financeiro, por parte das Autoridades Monetárias é, assim, bastante otimizado (Contel, 2011, p. 183).

No caso de São Paulo, inicialmente, optou-se pela privatização dos bancos estaduais Banespa e da Nossa Caixa, no entanto, no processo de venda do banco Nossa Caixa uma particularidade legal entrou em cena e viabilizou a formação da atual agência de fomento Desenvolve SP, já que houve um processo de segmentação na estrutura interna do banco Nossa Caixa, orquestrado antes mesmo de sua venda ao Banco do Brasil (ocorrida em novembro de 2008). Conforme a Lei Estadual n. 10.853/2001, artigo 9०, §1०-Lei que entre outras providências criou a Agência de Fomento do Estado de São Paulo (Afesp) (embrião da Desenvolve SP): "A administração dos Fundos Especiais de Financiamento e Investimentos será transferida para a Agência de Fomento do Estado de São Paulo, após a sua criação" (São Paulo, 2001). Isto é, com este artifício legal o segmento Fundos Especiais de Financiamento e Investimentos foi retirado da Nossa Caixa e transferido a outra entidade pois, aparentemente, mantê-lo se mostrava interessante ao governo do estado, tendo em vista a potencial venda do banco Nossa Caixa ao Banco do Brasil.

A Desenvolve SP foi concebida como instrumento institucional de apoio às políticas de desenvolvimento econômico para o estado de São Paulo e desembolsa recursos (i) para empresas localizadas no estado e (ii) para as prefeituras dos municípios paulistas.

Esta agência tem três grandes eixos de financiamento que envolvem agentes distintos:

i) eixo Programas de governo, em que atua em parceria com o governo do estado de São Paulo em projetos que visam o "estímulo ao desenvolvimento social e regional".

ii) eixo Municípios, em que oferece linhas de financiamento para o setor público, a juros baixos e prazos longos, para apoiar a administração municipal na realização dos investimentos necessários à infraestrutura da cidade sem comprometer o orçamento do município.

iii) eixo Empresas, em que atua financiando projetos, investimento, aquisição de máquinas e capital de giro para as pequenas e médias empresas paulistas que faturam a partir de $R \$ 360$ mil até $R \$ 300$ milhões. 
Dos três eixos apontados, aquele que mais interessa à nossa discussão, nesse momento, é o eixo Empresas, dada a importância dos agentes econômicos privados. Neste eixo, as linhas de financiamento oferecidas são: máquinas e equipamentos, capital de giro, franquias, fornecedores do Estado, BNDES (operadas pela Desenvolve SP com repasses do Banco Nacional de Desenvolvimento Econômico e Social - BNDES) e projetos de investimento. Esta última - projetos de investimento - ganha destaque especial por encampar significativas linhas de financiamento para a indústria paulista: (i) Financiamento ao investimento paulista: que financia projetos de implantação, ampliação e modernização da capacidade produtiva; (ii) Linha incentivo à tecnologia: financia projetos para o desenvolvimento e a transferência de tecnologia, criação de novos produtos, processos ou serviços, investimentos em infraestrutura e PED (Pesquisa e Desenvolvimento), que incorporem ganhos tecnológicos ou processos inovadores à empresa. Aponta-se que em julho de 2013 foi lançada uma linha de crédito especial, com foco em projetos de inovação tecnológica, em parceria com a Finep (Financiadora de Estudos e Projetos); (iii) Petróleo e gás natural: financia empresas ligadas à cadeia produtiva do setor de petróleo e gás natural, como: provedoras de infraestrutura, produtoras de insumos básicos, ferramentas, maquinários e equipamentos, indústria de bens de consumo, prestadoras de serviços em educação e capacitação técnica e serviços especializados.

Segundo dados da Desenvolve SP, em novembro de 2015, foram alcançados R 2 biIhões em desembolsos acumulados desde o início de suas atividades, sendo atendidas 1.370 empresas e prefeituras em 246 municípios paulistas. Do montante liberado, 67\%, teve como destino o interior do estado, enquanto a Região Metropolitana de São Paulo ficou com 33\%.

O Gráfico 1 permite a visualização dos desembolsos por setor e por ano desde a criação da Agência.

\section{Gráfico 1 - Desembolsos por setor (em \%)}

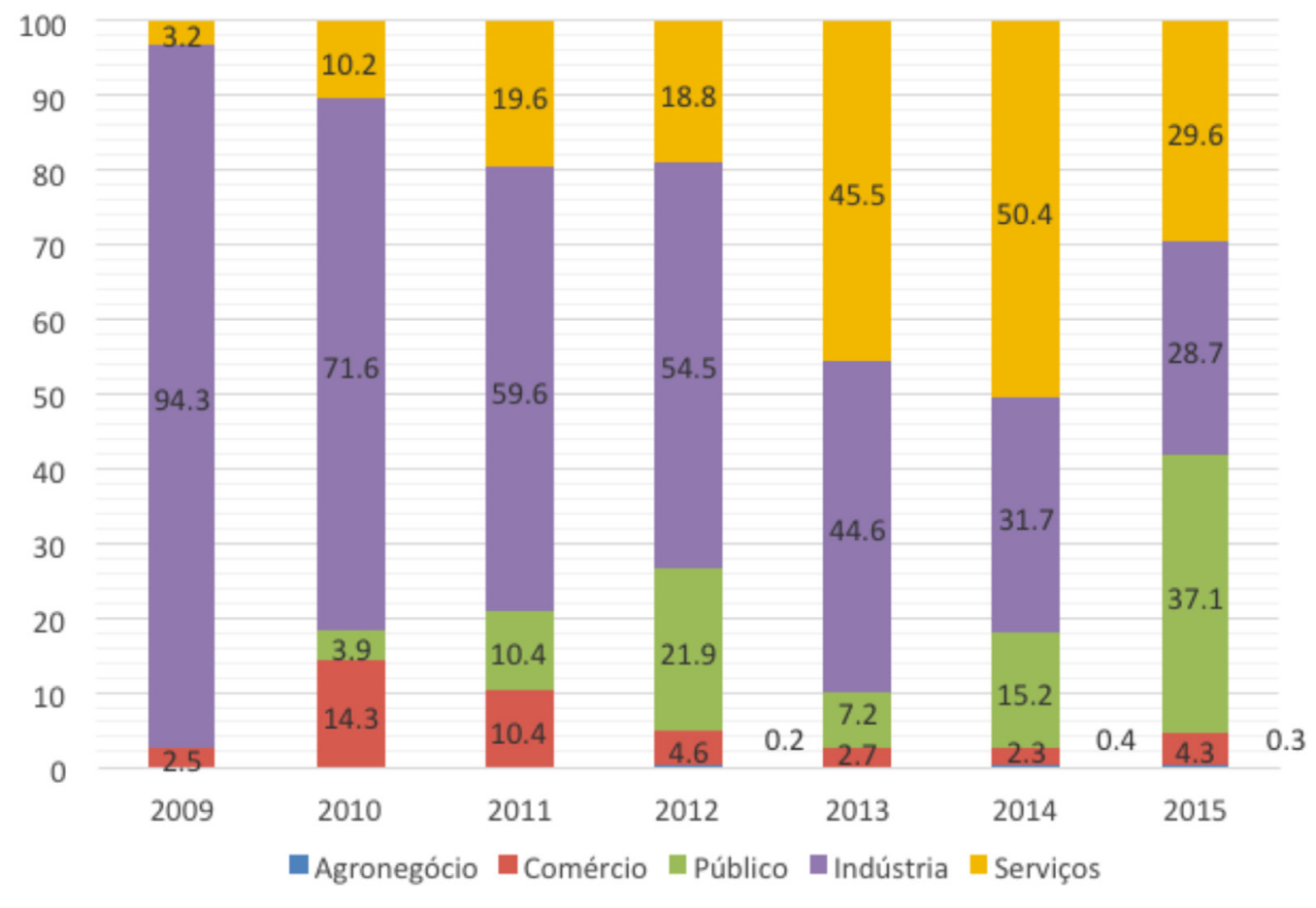

fonte: Baseado no Relatório da Administração (Desenvolve SP, 2015). 
Pode-se perceber que ao longo do período retratado os setores Indústria e Serviços foram os que mais se destacaram na obtenção de créditos. No entanto, conforme análise da própria Agência, em 2014 e 2015 estes dois setores, em função da retração de mercado, reduziram a demanda de crédito. Por conta disso, os financiamentos para o setor público, sobretudo os voltados à infraestrutura dos municípios, foram os que tiveram o melhor desempenho, somando 37,1\% do total desembolsado pela Agência em 2015.

○ Gráfico 2 aponta o desempenho das operações de crédito da Desenvolve SP. Pode-se notar a mudança da estratégia da Agência ao determinar desembolsos cada vez menos ao "capital de giro" em relação aos "projetos de investimento".

\section{Gráfico 2 - Desembolsos por segmento (em \%)}

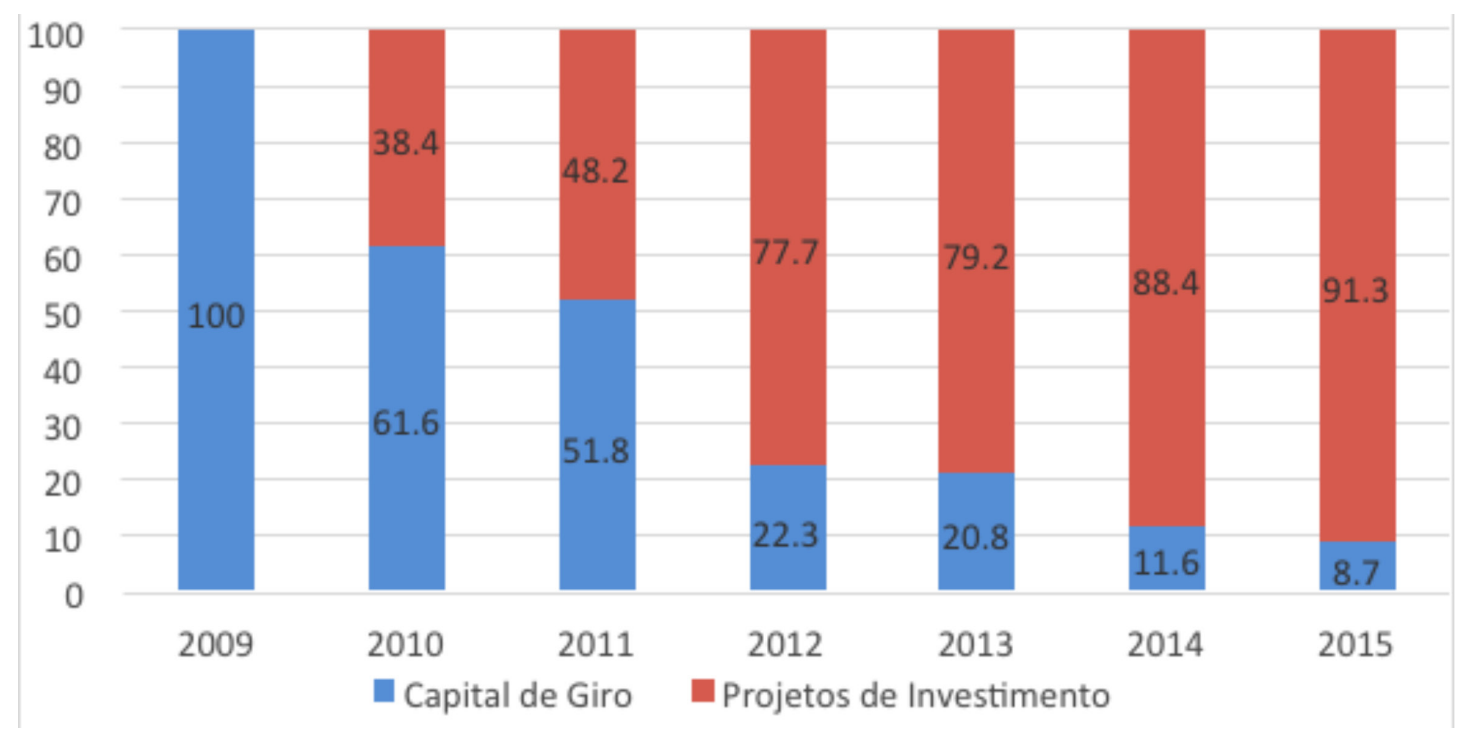

fonte: Baseado no Relatório da Administração (Desenvolve SP, 2015).

As operações de financiamento para projetos de investimento são as de maior representatividade, com expressiva representatividade a partir de 2012, essa situação aponta para a estratégia da Agência em se promover como instrumento para a viabilização da consolidação e ampliação da atividade produtiva em São Paulo, já que visa estimular o investimento e não apenas o giro do recurso do empresariado.

Convém apontar que a agência, desde o ano de 2014, tem realizado diversas parcerias com o objetivo de atrair empresas de determinados setores. Como exemplo desta afirmação, consta o fortalecimento da parceria entre a Desenvolve SP com a Associação Brasileira das Empresas de Software (ABES), juntamente com o Banco Nacional do Desenvolvimento Econômico e Social (BNDES), com uma proposta de juros de 4\%, valor inferior até mesmo para os padrões da agência de fomento que costuma aplicar juros de 6\% a 7\%.

O modo de relacionamento da Desenvolve SP para o eixo Empresas é bem específico: para operar com as firmas paulistas sua estratégia é atuar por meio de parcerias com entidades empresariais (atualmente conta com parcerias com 76 entidades). Além disso, conta com parcerias institucionais com agências e entidades internacionais: Aecid (Agência Espanhola de Cooperação Internacional e Desenvolvimento), por meio do Instituto 
Ambiental Brasil Sustentável e Endeavor Brasil - filial brasileira da principal instituição mundial de seleção e apoio a empreendedores de alto impacto, a Endeavor Global, que tem sede nos EUA.

Neste ponto é conveniente sugerir o questionamento de qual seria o papel dessas instituições ao se tornarem "parceiras" do Desenvolve SP, sobretudo as internacionais. Conforme o Decreto n. 52.142 de 6 de setembro de 2007 (São Paulo, 2007), que dispõe sobre a constituição e o funcionamento da Afesp (que deu origem ao Desenvolve SP), em seu Artigo 7०, inciso $\checkmark$ fica especificado que constituem fontes de recursos da Afesp: " $V$ - repasses originários de organismos e institutos financeiros nacionais e internacionais de desenvolvimento" (São Paulo, 2007). No atual período, os agentes da globalização, por meio dessas agências internacionais, podem impor estratégias e direcionamentos dos empréstimos àquelas empresas e setores mais "interessantes" ao mercado.

Outro ponto relevante dessa atuação é a relação do Estado (em suas várias escalas e pela Desenvolve SP) com as empresas, que também pressionam os entes subnacionais direta e indiretamente para a liberação de recursos para viabilizarem seus projetos. Basta, por exemplo, verificar os projetos para financiamento estatal para a construção de Distritos Industriais nos municípios paulistas, ou seja, o recurso público é destinado para a viabilidade da instalação e operação de empresas. Esta é uma das maneiras pela qual é praticada a política das empresas apontada por Santos (1997), já que a gestão e regulação do território são cada vez mais críticos porque as instâncias econômicas têm muito poder de interferência. Essa política seria caracterizada pela interferência direta nos orçamentos dos poderes públicos de equações parametrizadas segundo os lucros das empresas e não segundo os interesses gerais da sociedade. Pode-se objetar a essa "política das empresas", pois orçamentos públicos usados em interesses privados é um velho modo de se fazer política no país. Contudo, os interesses privados eram velados, mas hoje eles são explicitados e chegam a fazer parte dos orçamentos votados nas esferas legislativas.

\section{Considerações finais}

A prática de celebração de acordos para obter recursos públicos via empréstimos, no âmbito das agências de fomento dos entes estaduais, exige certo nível de racionalização dos procedimentos e certa articulação entre os agentes (estatais e privados).

O fio condutor de método de nossa discussão é a indissociabilidade entre lugar e formação socioespacial (Santos, 1977), ou em outras palavras, entre território e política, entre o território usado e a arquitetura da federação brasileira. Assim, acreditamos que entender a atuação da Desenvolve SP, especificamente no estado de São Paulo, pode trazer luz à nossa proposta inicial de debate, isto é, a de analisar e buscar compreender, a partir da ação estatal, o papel ativo do território na reorganização das solidariedades federativas. Concordamos com a visão de Limonad (2014) de que no Brasil evidencia-se cada vez mais o papel do Estado no processo de criação de condições gerais para acumular diferentes capitais. Segundo a autora, "o Estado assumiu e segue assumindo o papel de promotor, financiador e parceiro de diferentes capitais. $\bigcirc$ que tem levado a um fortalecimento de distintos grupos de interesse localizados" (Limonad, 2014, p. 12). 
Para Monteiro Neto (2013), nas últimas duas décadas, se consolida no Brasil, na maior parte dos entes estaduais, um quadro de restrições à ampliação da capacidade de investimento público e de perda de instrumentos (bancos e empresas estatais) para o financiamento do investimento. "Assim, aos governos estaduais não têm restado alternativas para promover determinadas estratégias de crescimento que não acirrar a guerra fiscal com as demais UF em torno de investimentos privados" (Monteiro Neto, 2013, p. 45). Apesar de concordar com os autores, entendemos que não há apenas uma disputa por meio da taxação fiscal, já que, além dela, os empréstimos e os financiamentos das Agências Estaduais de Desenvolvimento também se caracterizam como elementos atrativos e, somados à configuração territorial do lugar (infraestruturas instaladas, densidades técnica e normativa favoráveis etc.), caracterizam, em verdade, uma guerra de lugares (como apontado por Santos [1999b]).

Nesse processo de acirramento de disputas e desonerações fiscais como atrativos para a instalação de empresas, na federação brasileira, São Paulo já leva vantagem por ser o maior estado arrecadador de ICMS e IPVA (principais tributos cuja competência de arrecadação é estadual e os mais relevantes na composição do orçamento corrente estadual) e por ter um amplo mercado consumidor em potencial. Podemos dizer que, se por meio da Desenvolve SP o estado paulista estimular ainda mais a atividade industrial em seu território, é certo que haverá mais arrecadação desses tributos futuramente. Por isso, entendemos que o estado ganha duplamente: primeiro, por meio da agência estatal Desenvolve SP, que empresta um dinheiro que retorna com juros a seus cofres; depois, pela ampliação da capacidade produtiva das indústrias, que, portanto, pagam mais tributos ao próprio governo paulista.

\section{Referências}

ANTAS JR., R. M. Território e regulação: espaço geográfico, fonte material e não formal do direito. São Paulo: Humanitas/Fapesp, 2005.

BCB. BANCO CENTRAL DO BRASIL. Resolução n. 2828, de 30 de março de 2001. Dispõe sobre a constituição e o funcionamento de agências de fomento. Diário Oficial da União, 30 mar. 2001. Disponível em: http://www.bcb.gov.br/pre/normativos/ res/2001/pdf/res_2828_v6_P.pdf. Acesso em: 16 jun. 2017.

Resolução n. 2574, de 17 de dezembro de 1998. Dispõe sobre a constituição e o funcionamento de agências de fomento. Diário Oficial da União, 17 dez. 1998. Disponível em: https://www.bcb.gov.br/pre/normativos/busca/downloadNormativo.asp?arquivo=/Lists/ Normativos/Attachments/45231/Res_2574_vl_O.pdf. Acesso em: 16 jun. 2017

. Agências de Fomento. Bacen. Disponível em: http://www.bcb.gov.br/pre/composicao/af.asp. Acesso em: 27 maio 2015.

. Disponível em: http://www.bcb.gov.br/. Acesso em: 2 jul. 2015.

BRASIL. Medida Provisória no 2.192-70, de 24 de agosto de 2001. Estabelece mecanismos objetivando incentivar a redução da presença do setor público estadual na atividade financeira bancária, dispõe sobre a privatização de instituições financeiras, e dá outras providências.

Diário Oficial da União, Brasilia, DF, 25 ago. 2001. Disponível em: http://www.planalto.gov.br/ccivil_03/mpv/Antigas_2001/2192-70.htm. Acesso em: 16 jun. 2017. 
Medida Provisória n. 1514, de 7 de agosto de 1996. Estabelece mecanismos objetivando incentivar a redução da presença do setor público estadual na atividade financeira bancária, dispõe sobre a privatização de instituições financeiras, e dá outras providências. Diário Oficial da União, Brasília, DF, 8 ago. 1996. Disponível em: http://www. planalto.gov.br/ccivil_03/mpv/Antigas/1514.htm. Acesso em: 16 jun. 2017.

Artigo 192. Constituição da República Federativa do Brasil de 1988. Brasília, DF: Senado, 1988. Disponível em: http://www.planalto.gov.br/ccivil_03/constituicao/constituicaocompilado.htm.Acesso em: 16 jun. 2017

CASTELLS, M. Crise do Estado, consumo coletivo e contradições urbanas. In: POULANTZAS, N. (Org.). Estado em crise. Rio de Janeiro: Graal, 1977. p. 11-26.

CATAIA, M. Território usado e federação: articulações possíveis. Educação E Sociedade, Campinas, v. 34, n. 125, p. 1135-1151, 2013. Disponível em: http://www.scielo.br/scielo. php?script=sci_arttextEpid=S0101-73302013000400007. Acesso em: 3 maio 2016.

Território político: fundamento e fundação do Estado. Revista Sociedade $\boldsymbol{E}$ Natureza, Uberlândia, v. 23, n. 1, p. 115-125, abr. 2011. Disponível em: http://www.seer. ufu.br/index.php/sociedadenatureza/article/view/11531. Acesso em: 15 jun. 2016.

CONTEL, F. B. Território e finanças técnicas: normas e topologias bancárias no Brasil. São Paulo: Annablume, 2011.

DESENVOLVE SP. Agência de Desenvolvimento Paulista. Relatório da Administração, 2015. Disponível em: http://www.desenvolvesp.com.br/a2sitebox/arquivos/transparencia/1279.pdf. Acesso em: 16 jun. 2017.

ENGELS, F. A origem da família, da propriedade privada e do Estado. Rio de Janeiro: Civilização Brasileira, 1977.

GALLO, F. Elementos da formação territorial do Brasil: a federação nacional como evento geográfico. Boletim Campineiro de Geografia, Campinas, v. 4, n. 1, 2014. Disponível em: http://agbcampinas.com.br/bcg/index.php/boletim-campineiro/article/view/167. Acesso em: 20 abr. 2016.

Aspectos da reorganização das solidariedades federativas no território nacional: o engessamento tributário planejado no Brasil e a difusão seletiva do meio técnico-científico-informacional. Boletim Goiano de Geografia (Online), v. 33, n. 3, p. 355-372, 2013. Disponível em: http://www.revistas.ufg.br/index.php/bgg/article/view/27328. Acesso em: 5 ago. 2016.

GALVÃO, D. R. Agências de fomento: intervenção estatal e desenvolvimento social. Trabalho de Conclusão de Curso (Direito) - Setor de Ciências Jurídicas, Universidade Federal do Paraná, Curitiba, 2012.

GOTTMANN, J. A evolução do conceito de território. Boletim Campineiro de Geografia, Campinas, v. 2, n. 3, 2012. Disponível em http://agbcampinas.com.br/bcg/ index.php/boletim-campineiro/article/view/86 Acesso em: 29 jun. 2016. 
GRAMSCI, A. Cadernos do cárcere: Maquiavel, notas sobre o Estado e a política. Rio de Janeiro: Civilização Brasileira, 2000a. v. 3.

Cadernos do cárcere: os intelectuais, o princípio educativo, jornalismo. Rio de Janeiro: Civilização Brasileira, 2000b. v. 2.

GRUPPI, L. O conceito de hegemonia em Gramsci. Rio de Janeiro: Graal, 1978.

HARVEY, D. A produção capitalista do espaço. São Paulo: Annablume, 2005.

JESSOP, B. The future of the capitalist state. Cambridge: Polity Press, 2002.

LIMONAD, E. Estado, espaço e escala no Brasil: subsídios para a reflexão. Scripta Nova Revista Electrónica de Geografía y Ciencias Sociales, v. XVIII, n. 493, 2014.

MONTEIRO NETO, A. Governos estaduais no federalismo brasileiro: capacidades e limitações no cenário atual. Texto para discussão, n. 1894. Rio de Janeiro: IPEA, 2013.

MORAES, D. Comunicação, hegemonia e contra-hegemonia: a contribuição teórica de Gramsci. Revista Debates, Porto Alegre, v. 4, n. 1, p. 54-77, jan./jun. 2010.

NETO RIBEIRO, P. A. Agências de Fomento: ambientes institucional, legal e operacional. Revista Desenbahia, Salvador, v. 1, n. 1, set. 2004. Disponível em: http://www.desenbahia.ba.gov.br/uploads/2408201114587656Revistal_Set2004.pdf. Acesso em: 15 abr. 2015.

PINTO, E. C.; BALANCO, P. Estado, bloco no poder e acumulação capitalista: uma abordagem teórica. Revista de Economia Política (Online), v. 34, n. 1, p. 39-60, jan./mar. 2014.

POULANTZAS, N. O Estado, o poder, o socialismo. 4. ed. São Paulo: Graal, 2000. p. 129-129.

(Org.). O Estado em crise. Rio de Janeiro: Graal, 1977.

RAFFESTIN, C. Por uma geografia do poder. São Paulo: Ática, 1993.

RAMOS, L. C. S. A sociedade civil em tempos de globalização: uma perspectiva neogramsciana. Dissertação (Mestrado em Relações Internacionais) - Instituto de Relações Internacionais, Pontifícia Universidade Católica do Rio de Janeiro, Rio de Janeiro, 2005.

RIBEIRO, A. C. T. Pequena reflexão sobre categorias da teoria crítica do espaço: território usado, território praticado. In: SOUZA, M. A. A. (Org.). Território brasileiro: usos e abusos. Campinas: Edições Territorial, 2003. p. 29-40.

SAES, D. A questão da autonomia relativa do Estado em Poulantzas. Crítica Marxista, São Paulo, v. 1, n. 7, p. 46-66, 1998.

SALVIANO JR., C. Bancos Estaduais: dos problemas crônicos ao Proes. Brasília: Banco Central do Brasil, 2004. Disponível em: https://www.bcb.gov.br/htms/public/BancosEstaduais/livro_bancos_estaduais.pdf. Acesso em: 2 maio 2013.

SANTOS, M. A natureza do espaço: técnica e tempo, razão e emoção. São Paulo: Edusp, 2002. (Coleção Milton Santos, 1.) 
- $\bigcirc$ território e o saber local: algumas categorias de análise. Cadernos IPPUR, Rio de Janeiro, v. XII, n. 2, p. 15-26, 1999a.

. Guerra dos lugares. Folha de S. Paulo, São Paulo, 8 ago. 1999b. Caderno Mais!, p. 3. Da política dos Estados à política das empresas. Cadernos da Escola do Legislativo. Belo Horizonte, v. 3, n. 6, p. 3-191, jul./dez. 1997.

Oretorno do território. In: SANTOS, M.; SOUZA, M. A. A.; SILVEIRA, M. L. (Org.).

Território: globalização e fragmentação. São Paulo: Anpur/Hucitec, 1994. p. 15-20.

Sociedade e espaço: a formação social como teoria e como método. Boletim Paulista de Geografia, São Paulo, n. 54, p. 81-99, 1977.

et al. $\bigcirc$ papel ativo da geografia: um manifesto. ENCONTRO NACIONAL DE GEÓGRAFOS, 12., 2000, Florianópolis. Anais..., Florianópolis, 2000. p. 1-13.

; SILVEIRA, M. L. O Brasil: território e sociedade no início do século XXI. São Paulo: Record, 2001.

SÃO PAULO (Estado). Decreto n. 52.142, de 6 de setembro de 2007. Dispõe sobre a constituição e o funcionamento da Agência de Fomento do Estado de São Paulo (Afesp), e dá providências correlatas. Diário Oficial, São Paulo, p. 1, 7 set. 2007. Disponível em: https://www.al.sp.gov.br/norma/?id=73774. Acesso em: 24 abr. 2015.

. Lei n. 10.853, de 16 de julho de 2001. Autoriza o Poder Executivo a alienar ações de propriedade da Fazenda do Estado no capital social do Banco Nossa Caixa S.A. e a proceder à sua reorganização societária, bem como a criar a Agência de Fomento do Estado de São Paulo, e dá outras providências. Diário Oficial, São Paulo, p. 2, 17 jul. 2001. Disponível em: https://www.al.sp.gov.br/norma/?id=2741. Acesso em: 16 jun. 2017.

SILVEIRA, M. L. O lugar defronte os oligopólios. In: DANTAS, A.; TAVARES, M. A. A. Lugar-mundo: perversidades e solidariedades - encontros com o pensamento de Milton Santos. Natal: EDUFRN, 2011. p. 79-100.

Ao território usado a palavra: pensando princípios de solidariedade socioespacial. In: VIANA, A. L. D.; IBAÑEZ, N.; ELIAS, P. E. M. (Org.). Saúde, desenvolvimento e território. São Paulo: Aderaldo E Rothschild, 2009. p. 127-150.

VAINER, C. B. Lugar, região, nação, mundo: explorações históricas do debate acerca das escalas de ação política. Revista Brasileira de Estudos Urbanos e Regionais, v. 8, n. 2, p. 9-29, nov. 2006.

VERGOPOULOS, K. Estado e subdesenvolvimento. Economia e Desenvolvimento - Revista quadrimestral de Economia. São Paulo, v. 1, n. 3, p. 51-67, jun. 1982.

WEBER, M. Economia e sociedade: fundamentos da sociologia compreensiva. Brasilia: Ed. UnB, 1991. v. 1. 